\title{
Paradoxical vocal cord motion in the recovery room: a masquerader of pulmonary dysfunction
}

Purpose: We report a case of paradoxical vocal cord motion as an unusual cause of postoperative stridor and wheezing. A means of diagnosis and management is discussed.

Clinical findings: A 7I-yr-old man developed paradoxical vocal cord motion following uncomplicated hip replacement. He was treated with standard therapy for postoperative stridor and wheezing. After extensive evaluation, a flexible fibreoptic laryngoscope was used and the vocal cords noted to move paradoxically. This was the cause of his postoperative stridor and wheezing. Paradoxical vocal cord motion should be suspected as a cause of postoperative stridor and wheezing when the airway is easily maintained by a bag and mask, there is previous history of psychological problems, and there exists an unexplained history of previous postoperative airway distress. The definitive diagnosis may be made using a fibreoptic laryngoscope. In this patient, intubation was deferred and a plan of conservative therapy pursued.

Conclusion: Paradoxical vocal cord motion is an unusual cause of postoperative respiratory distress. A definitive diagnosis may be made by the use of a flexible fibreoptic laryngoscope using topical anaesthesia.

Objectif: Rapporter un cas de motilité paradoxale des cordes vocales comme cause de stridor et de wheezing postopératoires. Le diagnostic et la gestion de cette anomalie sont discutés.

\section{Key words}

AIRWAY: obstruction, vocal cords;

VENTILATION: obstruction, stridor.

From the Department of Anesthesiology, University of Wisconsin Clinical Science Center, Madison, Wisconsin.

Address correspondence to: Dr. George Arndt, Department of Anesthesiology, B6/319 CSC, 600 Highland Avenue,

Madison, WI 53792-3272, USA.

Phone: (608) 263-8100. Fax: (608) 263-0575.

E-mail: gaarndt@facstaff.wisc.edu

Accepted for publication July 20, 1996.
Éléments clinique: $A$ le suite un remplacement de la hanche sans complications, un homme de 71 a présenté une motilité paradoxale des cordes vocales. Il a été traité de la même façon que tout stridor et wheezing postopératoires. Après une évaluation soignée, une fibrolaryngoscopie flexible a montré que les cordes vocales remuaient paradoxalement, ce qui expliquait le stridor et le wheezing. Une motilité paradoxale des cordes vocales devrait être suspectée comme une cause de stridor et de wheezing postopératoires lorsque les voies aériennes sont maintenues facilement avec un ballon et un masque, lorsque le patient a déjà présenté des problèmes psychologiques et en face d'une histoire antérieure de difficulté postopératoire au niveau des voies aériennes. Le diagnostic définitif peut être fait par fibrolaryngoscopie. Chez ce patient, l'intubation a été retardée et un plan de traitement conservateur suivi.

Conclusion: La motilité paradoxale des cordes vocales constitue une rare cause de détresse respiratoire postopératoire. Un diagnostic définitif peut être réalisé par fibrolaryngoscopie flexible après une anesthésie de contact.

Paradoxical vocal cord motion (PVCM) is an unusual cause of airway distress and may masquerade as either acute bronchospasm or acute obstruction of the airway. We report a case of postoperative PVCM in a 71 -yr-old man following hip replacement. Paradoxical vocal cord motion should be suspected when no predisposition to airway disease exists, the airway is easily maintained using a bag and mask, the patient can follow verbal commands, and a history of psychiatric or emotional problems exists. It may also occur in patients with frequent admission to emergency rooms for asthma where the diagnosis is uncertain and refractory to standard therapy, in patients with Munchausen's syndrome, or in patients requiring postoperative intubation where the aetiology is uncertain. The definitive diagnosis of PVCM is made using indirect fibreoptic laryngoscopy. Paradoxical motion of the vocal cords is seen with the cords closing on inspiration. 


\section{Case report}

A 71-yr-old man was scheduled for elective left total hip arthroplasty. He had a history of smoking, rheumatoid arthritis, clinical depression, immunoblastic lymphoma in remission, anaemia and coronary artery disease. He had sustained a minor myocardial infarction $14 \mathrm{yr}$ earlier and was asymptomatic. Although he suffered left hip pain, he maintained an active lifestyle using a walker. He had undergone two previous operations, an uncomplicated right total knee arthroplasty in 1987 and revision in 1993. He denied previous anaesthetic problems and there were no drug allergies. However, after previous surgery, he had required tracheal intubation and monitoring in an intensive care unit for an uncertain reason following surgery in 1987. Current medication included aspirin, bumetanide, baclofen, potassium chloride, ranitidine, diazepam, nortriptyline, rifampim, cylcobenzaprine, oxycodone and a multivitamin. Preoperative laboratory evaluation was unremarkable except for a haematocrit of 34. The ECG showed normal sinus rhythm with an occasional premature atrial contraction and occasional premature ventricular contraction but no signs of myocardial ischaemia. Preoperative chest $x$-ray was normal. Physical examination revealed a $62 \mathrm{~kg}, 165 \mathrm{~cm}$, white man. The patient 'was edentulous and airway examination was normal: previous tracheal intubation had been easy. Premedicated was with $1 \mathrm{mg}$ midazolam $i v$. In the operating room, routine monitors were placed. A right radial arterial line was inserted prior to induction. Following preoxygenation, anaesthesia was induced with $250 \mu \mathrm{g}$ fentanyl, $250 \mathrm{mg}$ thiopentone and $200 \mathrm{mg}$ lidocaine $i v$. After an airway was achieved, $10 \mathrm{mg}$ vecuronium were administered. An additional $3 \mathrm{mg}$ were required intraoperatively. The trachea was intubated easily and its position was confirmed by capnography and auscultation. An oral gastric tube was inserted and the stomach emptied. Anaesthesia was maintained with isoflurane $0.4 \%$ to $0.7 \%$ (end-tidal) in $60 \%$ nitrous oxide. The patient was placed in the right lateral decubitus position and the arthroplasty begun. The procedure lasted for one hour and $45 \mathrm{~min}$. Following skin closure, the patient was placed supine. Muscle relaxation was reversed with $3 \mathrm{mg}$ neostigmine and $0.6 \mathrm{mg}$ glycopyrrolate. Full clinical reversal was noted using a peripheral nerve stimulator (PNS) by observing a full train of four and five seconds of sustained tetanus at $50 \mathrm{~Hz}$. The patient began to breathe spontaneously. Anaesthesia was discontinued, the oral gastric tube removed and the pharynx suctioned. The endotracheal tube was removed when the patient opened his eyes to verbal command.

The patient was transported to the recovery room.
Upon arrival, while monitors were placed, the patient's breathing become stridorous, primarily on inspiration. On chest auscultation, wheezing was present. The pulse oximeter indicated arterial saturation $\left(\mathrm{SpO}_{2}\right)$ of $85 \%$. The lungs were immediately ventilated with a bag and mask. The $\mathrm{SpO}_{2}$ returned to $100 \%$. The patient was responsive and followed verbal commands. An additional $1 \mathrm{mg}$ neostigmine and $0.2 \mathrm{mg}$ glycopyrrolate $i v$ were administered empirically as muscle relaxants had been administered previously. A PNS was placed over the ulnar nerve and again indicated sustained tetanus at 50 $\mathrm{Hz}$. Three $80 \mu \mathrm{g}$ doses of naloxone $i v$ were administered with no improvement in respiratory effort as fentanyl was administered intraoperatively. Following naloxone $i v$, eight aerosolized metered doses of both ipratroprium bromide and albuterol were administered over $15 \mathrm{~min}$ with no resolution as wheezing was present on the initial exam. A 12-lead ECG, to eliminate myocardial ischaemia as a cause of dyspnoea, demonstrated no acute changes. A chest $x$-ray, to rule out new onset pulmonary oedema, was unremarkable. When instructed to breathe slowly, the dyspnoea and stridor partially resolved. Because, on auscultation, the inspiratory stridor involved the upper airway, and reversible airway swelling may have been present from positioning, $1 \mathrm{mg}$ nebulized racemic epinephrine was administered with two $10 \mathrm{mg}$ doses decadron $i v$. The symptoms resolved over $20 \mathrm{~min}$.

Approximately $15 \mathrm{~min}$ later, stridor and dyspnoea returned. A second dose of nebulized racemic epinephrine was administered. A $70 \%$ helium-30\% oxygen mixture was administered by facemask with partial resolution. The patient maintained an $\mathrm{SpO}_{2}$ of $96 \%$ breathing at a rate of $24 \mathrm{bpm}$. Consideration was given to re-intubation. An ENT consultant, using a flexible nasal fibreoptic laryngoscope, demonstrated that the vocal cords moved paradoxically causing obstruction with inspiration. Conservative therapy was recommended. Over the next $90 \mathrm{~min}$, the symptoms abated with $0.4 \mathrm{mg}$ hydromorphone iv for pain control and anxiety, increased level of consciousness, and verbal reassurance. The patient was later transferred to the ward breathing 3 $\mathrm{L} \cdot \mathrm{min}^{-1} \mathrm{O}_{2}$ and was monitored that evening with pulse oximetry.

On the postoperative visit, there were no major anaesthetic complications. The patient again denied anaesthetic problems. However, on further questioning, he reported previously requiring emergency intubation after surgery.

\section{Discussion}

Patients in acute respiratory distress present a clinical dilemma for the anaesthetist. This patient presented in 
an unusual fashion with PVCM. The diagnosis was made by clinical suspicion and fibreoptic laryngoscopy. To the best of our knowledge, the use of indirect laryngoscopy has not been reported to make the diagnosis of PVCM in the post operative patient.

Paradoxical motion of the vocal cords (PVCM) was first reported by Rogers in 1978. ' Clinically, PVCM is a great masquerader and can present as stridor, bronchospasm, laryngospasm or airway obstruction. ${ }^{2-6}$ Paradoxical motion of the vocal cords usually presents with good oxygenation and a slight respiratory alkalosis but may be associated with hypoxaemia.,8 The clinician should suspect PVCM when no strong history of underlying pulmonary disease or airway problem exists, and a previous history of emotional problems or psychological problems is present. $3,9,11$ The precipitating event is usually psychological stress. ${ }^{3}$

In acute cases of PVCM, there is a complete or marked improvement of symptoms with intermittent positive pressure ventilation using a bag and mask, CPAP, or administering a helium-oxygen mixture by face mask. ${ }^{711}$ The physiological mechanism of PVCM is unclear, but involves the brainstem inspiratory centre when phase reversal occurs between the inspiratory neurons and the vocal cord motor neurons. ${ }^{7}$ In many patients, there is a strong psychological component and PVCM is a conversion reaction. The diagnosis is made by fibreoptic laryngoscopy. The vocal cords adduct on inspiration causing partial or complete obstruction of the airway at the glottis. In the non-acute setting, diagnosis is aided by spirometry, and flow volume curves may show an extrathoracic air-flow obstruction. ${ }^{6.7}$ The management of postoperative PVCM is first to rule out common causes of respiratory difficulty. These include inadequate neuromuscular relaxant reversal, an assessment of the level of consciousness due to the use of opioids, benzodiazepines and residual volatile anaesthetics, and assessment of an exacerbation of underlying cardiac or pulmonary pathology. Therapies reported include bronchodilators, iv steroids, IPPV, CPAP, and helium-oxygen by face mask. ${ }^{6,7,9,10}$ Psychological reassurance and instructions to breath in a slow pattern which minimizes inspiratory obstruction may also resolve symptoms. The severity of PVCM can vary greatly. In patients presenting with unresolved hypoxaemia and cyanosis, definitive management is tracheal intubation and mechanical ventilation.

\section{Conclusion}

This case demonstrates a case of PVCM in which the diagnosis was made by indirect laryngoscopy. It should be considered as a cause of airway distress in the acute setting and may present as stridor, dyspnoea or wheez- ing. Although the basic considerations of providing an airway, adequate oxygenation and ventilation take priority, in patients with PCVM, where oxygenation and ventilation can be maintained, airway examination may be performed and conservative management pursued. The diagnosis should be suspected when there is no underlying aetiology, there is a history of psychological problems, or of frequent visits to the emergency room for asthma, or of Munchausen's syndrome. In stable patients, definitive diagnosis is made using fibreoptic laryngoscopy and observing the paradoxical vocal cord motion. There may be a previous history of respiratory difficulty following surgery.

\section{References}

1 Rogers JH, Stell PM. Paradoxical movement of the vocal cords as a cause of stridor. J Laryngol Otol 1978; 92: 157-8.

2 Heiser JM, Kahn ML, Schmidt TA. Functional airway obstruction presenting as stridor: a case report and literature review. J Emerg Med 1990; 8: 285-9.

3 Brown TM, Merritt WD, Evans DL. Psychogenic vocal cord dysfunction masquerading as asthma. J Nerv Ment Dis 1988; 176: 308-10.

4 Kellman RM, Leopold DA. Paradoxical vocal cord motion: an important cause of stridor. Laryngoscope 1982; 92 : 58-60.

5 Appelblatt NH, Baker SR. Functional upper airway obstruction. A new syndrome. Archives of Otolaryngology 1981; 107: 305-6.

6 Downing ET, Braman SS, Fox MJ, Corrao WM. Factitious asthma. Physiological approach to diagnosis. JAMA 1982; 248: 2878-81.

7 Collett PW, Brancatisano T, Engel LA. Spasmodic croup in the adult. Am Rev Respir Dis 1983; 127: 500-4.

8 Christopher KL, Wood RP II, Eckert RC, Blager FB, Raney $R A$, Souhrada JF. Vocal-cord dysfunction presenting as asthma. N Engl J Med 1983; 308: 1566-70.

9 Rodenstein DO, Francis C, Stanescu DC. Emotional laryngeal wheezing: a new syndrome. Am Rev Respir Dis 1983; 127: 354-6.

10 Kivity S, Bibi H, Schwarz Y, Greif Y, Topilsky M, Tabachnick E. Variable vocal cord dysfunction presenting as wheezing and exercise-induced asthma. J Asthma 1986; 23: 241-4.

$11 O^{\prime}$ Hollaren $M T$. Masqueraders in clinical allergy: laryngeal dysfunction causing dyspnea. Ann Allergy 1990; 65 351-6. 